\title{
«Le Moyen Français» 76-77
}

\section{Maria Colombo Timelli}

\section{(2) OpenEdition \\ Journals}

Édition électronique

URL : http://journals.openedition.org/studifrancesi/9896

DOI : 10.4000/studifrancesi.9896

ISSN : 2427-5856

\section{Éditeur}

Rosenberg \& Sellier

\section{Édition imprimée}

Date de publication : 1 août 2017

Pagination : 335-336

ISSN : 0039-2944

\section{Référence électronique}

Maria Colombo Timelli, « «Le Moyen Français» 76-77 », Studi Francesi [En ligne], 182 (LXI | II) | 2017 , mis en ligne le 01 août 2017, consulté le 06 janvier 2021. URL : http://journals.openedition.org/ studifrancesi/9896 ; DOI : https://doi.org/10.4000/studifrancesi.9896

Ce document a été généré automatiquement le 6 janvier 2021.

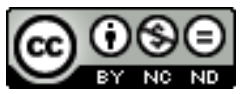

Studi Francesi è distribuita con Licenza Creative Commons Attribuzione - Non commerciale - Non opere derivate 4.0 Internazionale. 


\title{
«Le Moyen Français» 76-77
}

\author{
Maria Colombo Timelli
}

\section{RÉFÉRENCE}

«Le Moyen Français» 76-77, 2015.

1 Ce fascicule du «Moyen Français» réunit les contributions à un séminaire qui s'est déroulé à l'Université de Paris 3 de 2012 à 2015: centré sur l'emploi du vers et de la prose au Moyen Âge, il avait pour but d'interroger les textes sur la pratique de ces formes d'une part, sur leur théorisation éventuelle de l'autre. Les corpus examinés, ainsi que les langues en jeu, sont assez diverses et prouvent bien que plusieurs domaines et aires linguistiques participent d'un véritable débat, souvent implicite, sur le rapport entre les deux écritures entre XIII et début du XVI ${ }^{\mathrm{e}}$ siècle.

2 Adrian ARMSTRONG examine un corpus de douze traductions en néerlandais de vers ou de prosimètres français de la seconde moitié $\mathrm{du}_{\mathrm{xv}} \mathrm{v}^{\mathrm{e}}$ siècle (outre la Consolatio de Boèce, récupérée ici en tant que pièce maîtresse, les auteurs retenus sont Jean Molinet, Jean Lemaire de Belges, Nicaise Ladam, Pierre Gringore, Amé de Montgesoie, Olivier de La Marche, Jean Bouchet, Pierre Michault), dans le but de vérifier les techniques adoptées surtout en relation à la forme: l'analyse permet de reconnaitre que, globalement, le vers «revêt un caractère de supplément formel» dans les deux cultures (p. 29) que les traducteurs s'efforcent de maintenir ( «Half dicht, half prose gheordineert». Vers et prose de moyen français en moyen néerlandais, pp. 7-38; dossier des textes aux pp. 30-38).

3 Sur la base de neuf romans rédigés dans l'atelier du Maître de Jean de Wavrin (Blancandin, Florimont, Florent et Octavien, Gérard de Nevers, Jehan d'Avennes, Chastelain de Coucy, Gilles de Chin, Seigneurs de Gavre, Comte d'Artois), Annie comBEs montre comment un cercle d'auteurs anonymes adoptent une pratique variable de réfection de leurs textes de départ, pour la plupart mais non exclusivement des sources en vers; cette pratique ne s'accompagne cependant d'aucune réflexion sur le traitement de ces modèles, ni sur le rapport vers-prose, et encore moins d'une explicitation du rôle de l'écrivain ou de l'opération de réécriture qu'il a effectuée. Si une «école» a existé à Lille 
autour de 1450, elle peut être reconnue par des analogies dans la production et l'illustration de ces manuscrits, le silence voire les mensonges que ces auteurs ont glissés dans leurs prologues ne révélant de fait qu'une «pratique non réfléchie» et une «familiarité avec les œuvres qui circulent, à l'écart de toute réflexion critique» (L'athanor de la prose (l'atelier de Jean de Wavrin), pp. 39-64, citation p. 63).

4 Noémie CHARDONNENS s'attache aux huit lais enchâssés dans Perceforest; tous rattachés à la sphère amoureuse, ils entretiennent un lien étroit avec le récit, et ce sur plusieurs plans: soit ils reviennent sur des moments de la narration déjà racontés en prose, soit ils provoquent les réactions des destinataires internes ou des lecteurs, soit encore ils relancent l'action. L'auteur dépasse ainsi largement ses modèles, le Tristan en prose au premier chef, mais également Ysaÿe le Triste et Meliadus: dans Perceforest, vers et prose, plutôt qu'opposés, s'avèrent complémentaires (Mémoire de la prose, destin du vers. Les lais $d u$ "Perceforest" du Xve au XvI siècle, pp. 65-84).

5 Éditrice avec Didier Lechat du Livre du duc des vrais amants (Paris, Champion, 2013), Dominique DEMARTINI interroge la fonction du vers et de la prose dans cette œuvre de Christine de Pizan. Comparé d'abord avec le Roman de la Rose de Guillaume de Lorris, le Livre révèle une distribution réfléchie du vers narratif, de la prose didactique dans les épîtres enchâssées, et encore des vers lyriques; à ces différentes formes s'ajoute le recueil final de pièces poétiques, retranché du récit, où c'est la voix féminine qui prend le dessus («Des or est mout changiez li vers». Fictions du vers et de la prose dans "Le Livre du duc des vrais amants" de Christine de Pizan, pp. 85-109).

6 Témoignage intéressant d'une écriture de l'histoire en milieu urbain au début du $\mathrm{XVI}^{\mathrm{e}}$ siècle, la Chronique de Philippe de Vigneulles contient tant des citations en vers que des résidus de la mise en prose du cycle des Lorrains du même auteur. Catherine M. JONES analyse très clairement les modalités d'insertion de ces pièces rapportées, ainsi que leurs multiples fonctions au sein d'une œuvre qui célèbre avant tout la ville de Metz et sa région (Zones de contact entre vers et prose dans la 'Chronique' de Philippe de Vigneulles, pp. 111-135).

7 Rédigé en prose, le Bestiaire d'Amours de Richard de Fournival a inspiré des réfections en vers: cette pluralité de versions permet à Sarah KAY de comprendre ce choix de la prose à une époque charnière - le début du XIII ${ }^{e}$ siècle - dans le rapport qui s'établit entre trois formes: vers, prose et chant (Chant et désenchantement dans le "Bestiaire d'Amours" de Richard de Fournival, pp. 137-158).

8 Amandine mussou examine quant à elle la relation qui s'instaure entre vers et prose lors du passage des Eschés amoureux (ca 1370-1380) à la «moralisation» fournie par Évrart de Conty vers la fin du XIve siècle. Si le commentaire d'Evrard se propose d'élucider le sens caché de la première partie du poème (environ un cinquième), l'intérêt du texte second réside aussi dans la rénovation lexicale et linguistique qu'il propose et dans le fait que l'œuvre ainsi glosée, et traitée à l'instar d'une auctoritas, est en fait un poème en vers français (Fiction et commentaire chez Évrart de Conty, des "Eschés amoureux" en vers au "Livre des eschez amoureux moralisés" en prose, pp. 159-184).

9 Morceau de bravoure poétique, tant par son bilinguisme que par sa complexité formelle, la lettre de Grâce de Dieu insérée dans le Pèlerinage de l'âme de Guillaume de Digulleville (ca 1356) subit une double translation sous la plume de Jean Galopes, qui la transpose en prose française entre 1422 et 1427, puis, à peu de distance, en prose latine. La collation attentive des trois textes menée par Stéphanie LE BRIZ et Géraldine 
VEYSSEYRE confirme, d'une part, que Galopes a fondé cette dernière adaptation sur sa propre prose française, sans nullement revenir aux vers latins de Guillaume, d'autre part que, si le texte français constitue une véritable réécriture du modèle versifié, la traduction latine implique à la fois une simplification des aspects théologiques et une transposition linguistique destinée à un nouveau public (Dérimer la lettre bilingue de Grâce de Dieu (Guillaume de Digulleville, "Le Pèlerinage de l'âme", vers 1593 à 1784), pp. 185-211).

10 Malgré une édition critique qui ne lui rend pas justice (par Claude M.L. Lévy, Université d'Ottawa, 1983), Florian et Florete en prose est une adaptation qui mérite d'être relue, comme le fait Barbara WAHLEN sur la base de la taxonomie proposée par Annie Combes dans un article récent, vite devenu une référence (L'emprise du vers dans les mises en prose romanesques (XIII ${ }^{\mathrm{e}} \mathrm{XV} \mathrm{e}^{\mathrm{s}}$ sècles), in Le Moyen Âge par le Moyen Âge, même. Réception, relectures et réécritures des textes médiévaux dans la littérature française des XIV et $X V^{e}$ siècles, Paris, Champion, 2012, pp. 115-140). On peut reconnaître ainsi que le prosateur anonyme du $\mathrm{XV}^{\mathrm{e}}$ siècle soumet à des traitements différents les scènes courtoises et les scènes épiques de sa source, et qu'il alterne les modalités de réécriture (de la transposition "contrainte» à la transposition «fidèle» à la transposition «libre») sur la base de choix délibérés et discernables (Transporter de rime en prose. L'exemple de "Floriant et Florete", pp. 213-230).

11 Si la réflexion sur le rapport entre vers et prose, entre autres sur ce produit typiquement français que sont les «mises en prose», a pris beaucoup d'ampleur ces dernières années, on reconnaîtra volontiers à ce fascicule du «Moyen Français» un grand intérêt, dans la mesure où les contributions qu'il réunit adoptent une approche large, tant pour la diachronie envisagée que pour les genres étudiées, et encore pour les langues concernées: on revient ainsi, en l'enrichissant de manière remarquable, sur un sujet qui, loin de ne concerner que les aspects formels et linguistiques, touche à l'univers culturel et mental des écrivains entre XIII ${ }^{e}$ et $\mathrm{Xv}^{\mathrm{e}}$ siècle. 